\title{
Selenium and Type 2 Diabetes: Systematic Review
}

\author{
Lindsay N. Kohler ${ }^{1,2, *}$, Janet Foote ${ }^{2}$, Connor P. Kelley ${ }^{2}$, Ana Florea ${ }^{2,3}{ }^{\oplus}$, Colleen Shelly ${ }^{4}$, \\ H-H Sherry Chow ${ }^{5}$, Paul Hsu ${ }^{2,5}$, Ken Batai ${ }^{6}$, Nathan Ellis ${ }^{5} \odot$, Kathylynn Saboda ${ }^{5}$, \\ Peter Lance $^{3,5}$ and Elizabeth T. Jacobs ${ }^{2,5}$ \\ 1 Department of Health Promotion Sciences, Mel and Enid College of Public Health, University of Arizona, \\ Tucson, AZ 85724, USA \\ 2 Department of Epidemiology, Mel and Enid College of Public Health, University of Arizona, Tucson, \\ AZ 85724, USA; jfoote@email.arizona.edu (J.F.); cpkelley@email.arizona.edu (C.P.K.); \\ aflorea@email.arizona.edu (A.F.); pchhsu@email.arizona.edu (P.H.); jacobse@email.arizona.edu (E.T.J.) \\ 3 Department of Medicine, University of Arizona, Tucson, AZ 85724, USA; plance@uacc.arizona.edu \\ 4 Department of Epidemiology, Harvard T.H. Chan School of Public Health, Boston, MA 02115, USA; \\ colleenshelly@gmail.com \\ 5 Department of Medicine, University of Arizona Cancer Center, Tucson, AZ 85724, USA; \\ schow@email.arizona.edu (H.-H.S.C.); naellis@email.arizona.edu (N.E.), ksaboda@email.arizona.edu (K.S.) \\ 6 Department of Surgery, University of Arizona, Tucson, AZ 85724, USA; kbatai@email.arizona.edu \\ * Correspondence: lschulz@email.arizona.edu; Tel.: +1-520-626-3357
}

Received: 24 October 2018; Accepted: 29 November 2018; Published: 5 December 2018

\begin{abstract}
Several studies have investigated the potential role of selenium (Se) in the development of type 2 diabetes (T2D) with disparate findings. We conducted a systematic review and meta-analysis to synthesize the evidence of any association between Se and T2D. PubMed, Embase, and Scopus were searched following the Preferred Reporting Items for Systematic Reviews and Meta-analysis Approach (PRISMA). Sixteen studies from 15 papers met inclusion criteria defined for this review. Of the 13 observational studies included, 8 demonstrated a statistically significant positive association between concentrations of Se and odds for T2D, with odds ratios (95\% confidence intervals) ranging from 1.52 (1.01-2.28) to 7.64 (3.34-17.46), and a summary odds ratio (OR) (95\% confidence interval (CI)) of 2.03 (1.51-2.72). In contrast, among randomized clinical trials (RCTs) of Se, a higher risk of T2D was not observed for those who received Se compared to a placebo (OR $=1.18,95 \%$ CI $0.95-1.47$ ). Taken together, the results for the relationship between Se and T2D differ between observational studies and randomized clinical trials (RCTs). It remains unclear whether these differences are the result of uncontrolled confounding in the observational studies, or whether there is a modest effect of Se on the risk for T2D that may vary by duration of exposure. Further investigations on the effects of Se on glucose metabolism are needed.
\end{abstract}

Keywords: type 2 diabetes; selenium; selenium supplementation; glucose; insulin resistance; review

\section{Introduction}

The trace element selenium (Se) gained momentum as a potential chemopreventive agent with the publication of the results of the Nutritional Prevention of Cancer (NPC) trial in 1996 [1]. In this randomized, double-blind chemoprevention trial, participants were supplemented with either $200 \mu \mathrm{g}$ Se per day as brewer's yeast or a matched placebo [1]. No benefit of Se supplementation was observed for the primary endpoint of the trial, non-melanoma skin cancer. However, secondary analyses revealed a statistically significant $58 \%$ reduction in colorectal cancer incidence and a $63 \%$ reduction in prostate cancer for those in the Se supplementation arm compared to those who received the placebo [1] and a longer-term follow-up demonstrated that this effect was attenuated [2]. 
The primary NPC results were followed by the work of Stranges et al., which showed that participants in the trial who were supplemented with Se had a statistically significantly higher rate of type 2 diabetes (T2D) than those in the placebo group (HR (95\% CI) of 1.55 (1.03-2.33)) [3]. Furthermore, those in the highest tertile for blood Se levels at baseline before administration of Se supplementation had a significantly higher risk of T2D than those with lower baseline Se levels (HR ( $95 \%$ CI) of 2.70 $(1.30-5.61))$ [3]. These results were unexpected given that Se was first hypothesized to potentially reduce the risk for insulin resistance and T2D given that the treatment of mice with selenate, an inorganic form of Se, resulted in insulin-like effects and mitigated insulin resistance [4,5]. In contrast to studies with rodent models, human studies have tended to focus on proteins that incorporate the amino acids selenomethionine and selenocysteine [6]. Glutathione peroxidase-1 (GPx-1) is a selenoprotein that has garnered a great deal of attention due to its beneficial ability to scavenge reactive oxygen species and prevent oxidative damage [6-8]. However, studies in rodent models have indicated that there is a potentially harmful effect of GPx-1. When it is overexpressed, it causes hyperglycemia; GPx-1 knockout mice have better glucose homeostasis compared to wild-type animals $[9,10]$. These findings may also suggest that a key feature of Se in glucose homeostasis depends on a balance of meeting Se nutritional requirements and avoiding excess exposure. Thus, since the publication of the results of the NPC trial related to Se and T2D, several later studies also assessed this association, with equivocal results.

The aim of the present study was, therefore, to conduct a review of the literature to evaluate and synthesize the evidence from studies on the association between selenium and T2D.

\section{Materials and Methods}

\subsection{Methods}

Search Strategy and Identification of Studies

The protocol was registered with PROSPERO, an international prospective register of systematic reviews (Ref: CRD42018081073). We employed the preferred reporting items for systematic reviews and meta-analysis approach (PRISMA) guidelines to conduct the systemic review [11]. We used the search terms "Selenium and type 2 diabetes", "selenium", "diabetes", "glucose", and "selenium supplementation" in the PubMed, Embase, and Scopus databases in November 2017. We restricted the search to include only human studies, English-language publications, and full-text articles from the past 15 years. We saved the PubMed search parameters and re-ran the query each month to identify and include new publications, and further checked each eligible article for references that may have been missed through the search.

Two reviewers (L.N.K. and A.F.) reviewed all identified titles and abstracts from the studies identified initially and a data extraction form was developed that included the first author's name, title, year of publication, study population, study design, length of follow-up period, study endpoints (development of T2D; glucose levels), and the point estimates of the original publication. Bias was assessed in all included studies using The Critical Appraisal Skills Programme's: Making Sense of Evidence [12]. Parameters included in the evaluation of bias were recruitment procedures, assessment technique for the exposure, outcome and any potential confounders, and generalizability of the work. Any discordant selections of studies for inclusion were resolved by a third reviewer (E.T.J.).

\subsection{Inclusion and Exclusion Criteria}

Any observational study published within the past 15 years with at least 100 participants that evaluated Se supplementation or measured Se status with T2D as an outcome was included; while all clinical trials with data available for both the numerator and denominator were included. The minimum criteria for inclusion were (1) Se supplementation or measured levels in whole blood, serum or plasma, or estimates of dietary intake of Se obtained from food frequency questionnaires; and (2) 
a reported outcome of T2D. Type 2 diabetes was defined at follow-up by self-report or measured by fasting blood sugar $>126 \mathrm{mg} / \mathrm{dL}$ on two separate tests or a glucose level of $>200 \mathrm{mg} / \mathrm{dL}$ after two hours during an oral glucose tolerance test (OGTT). Articles written in languages other than English were excluded as they could not be adequately reviewed by the research team. In addition, commentaries that did not present original data were excluded from the present analysis. Authors of potentially eligible published reports that lacked key information, such as the number of cases and controls, were contacted for the missing information. If this information was not forthcoming, various ranges of the T2D incidence rate for the lowest Se quantile, including the average of the T2D incidence rate among the studies with information available, and the reported odds ratio were used to derive the number of cases and controls for both the lowest and highest Se quantiles. This sensitivity analysis strategy indicated how sensitive the summary statistic was to those studies.

\subsection{Statistical Analysis}

Weighted summary estimates and 95\% confidence intervals (CIs) were obtained by random-effects meta-analysis by study design, which accounts for the between-study variation. For studies that did not report the number of type 2 diabetes cases in both the lowest and highest quantiles, an average prevalence of type 2 diabetes for the lowest quantile group from other studies was calculated. A sensitivity analysis was conducted with varying T2D prevalence rates (5-10\%), based on other studies in this review that provided prevalence information. Cochran's $Q$ was used to examine the presence of heterogeneity of treatment effects across included studies $(p<0.1)$. Further, the $I^{2}$ statistic was examined to quantify the presence of heterogeneity, with a value $>50 \%$ indicating significant heterogeneity. Publication bias was assessed via funnel plot visual inspection, while the meta-analysis was performed using the R package "metafor" (R version 3.5.0, Vienna, Austria).

\section{Results}

As shown in Figure 1, a total of 504 potentially relevant studies were reviewed; after the removal of duplicates and exclusion on the basis of title or abstract, 41 full papers evaluating Se and T2D were retained for in-depth consideration.

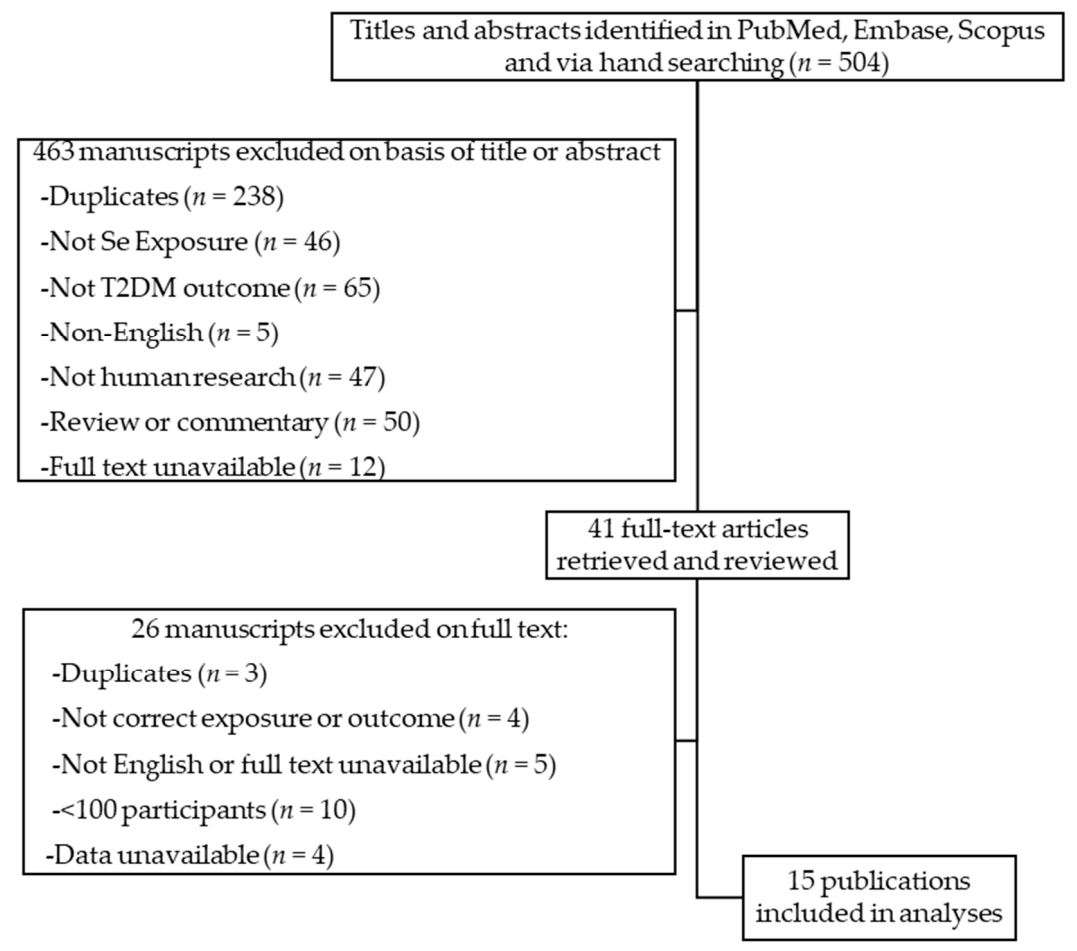

Figure 1. Manuscript selection flowchart. 
We identified 15 manuscripts that met the a priori criteria for inclusion. These are described in more detail in Table 1. These studies represent analyses of data from observational studies, as well as supplementation trials. All trials and observational studies mentioned fulfillment of ethics board approval criteria, except for Laclaustra et al. [13] and Bleys et al. [14], both of which utilized data from the National Health and Nutrition Examination Survey (NHANES), a publicly available dataset.

\subsection{Observational Studies}

The three longitudinal studies that were included followed a total of 9352 participants. The Uppsala Longitudinal Study of Adult Men (ULSAM, $n=936$ men) [15] included 20 years of follow-up, while the HORmones and Diet in the ETiology of Breast Cancer Study (ORDET, $n=7182$ women) [16] followed participants for 16 years. The third cohort was from the Hortega Study and included both men and women $(n=1234)$ and followed for an average of 13.2 years [17]. The ORDET study investigated dietary and/or supplemental selenium intake via baseline food frequency questionnaires, while the ULSAM study utilized baseline serum and the Hortega study, plasma [15-17]. Five case-control studies met inclusion and exclusion criteria, altogether comprising 1330 cases and 3664 controls [18-22]. All five studies evaluated biochemical selenium status via plasma $(n=1)$ [18], serum $(n=1)$ [21], or whole blood $(n=3)[19,20,22]$. There were also five cross-sectional studies included, with a total of 18,382 participants, published between 2007 and 2018 [13,14,17,23,24]. Wei et al. investigated dietary and/or supplemental selenium intake via food frequency questionnaires [24]. The remaining four cross-sectional studies evaluated biochemical selenium status via plasma $(n=2)[17,23]$ or serum $(n=2)[13,14]$.

\subsection{Randomized Controlled Trials}

We included three randomized clinical trials (RCTs), with a combined total of 20,290 participants, in this review $[3,25,26]$. All three trials assessed cancer or precancerous lesions as a primary outcome; however, the Selenium and Vitamin E Cancer Prevention Trial (SELECT) [25] $(n=17,448)$ enrolled only men, while the NPC trial $(n=1202)$ and the Selenium Trial $(n=1640)$ included men and women $[3,26]$. For each trial, investigators randomized participants to receive a $200 \mu \mathrm{g} /$ day Se supplement as either selenized yeast [3,26] or $L$-selenomethionine [4] or a matched placebo for an average of 5.4 years (range 3.0 to 7.7 years).

\subsection{Risk Assessment and Heterogeneity}

We evaluated ORs of highest versus lowest quantile of Se level for observational studies and Se level in Se intervention versus placebo groups for RCTs to assess the association between Se exposure and risk of T2D. As shown in Figure 2, observational study participants in the highest Se quantiles had a statistically significant increased odds of T2D compared to those in the lowest quantiles (pooled $\mathrm{OR}=2.03,95 \%$ CI $1.51-2.72$ ). 
Table 1. The 15 manuscripts that met the a priori criteria for inclusion.

\begin{tabular}{|c|c|c|c|c|}
\hline Author, Year & Study Population & Exposure Mean (SD) $\mu \mathrm{g} / \mathrm{L}$ & Covariates & Key Findings RR $(95 \% \mathrm{CI})$ \\
\hline Li et al. 2017 [18] & $\begin{array}{l}\text { Jiangsu Province; } 122 \text { newly } \\
\text { diagnosed cases, } 429 \text { matched } \\
\text { controls }\end{array}$ & $\begin{array}{l}\text { Plasma Se } \\
16.4(11.9)^{*}\end{array}$ & $\begin{array}{l}\text { Age, gender, BMI, family history, smoking and drinking } \\
\text { status }\end{array}$ & $\mathrm{OR}=6.14(3.01-12.51)$ \\
\hline Hansen et al. 2017 [19] & $\begin{array}{l}\text { The HUNT Study; } 128 \text { cases, } 755 \\
\text { controls }\end{array}$ & $\begin{array}{l}\text { Whole blood Se } \\
101.2 \text { cases } \\
101.4 \text { controls \# }\end{array}$ & $\begin{array}{l}\text { Age, sex, BMI, WHR, education, income, smoking, } \\
\text { family history of diabetes }\end{array}$ & $\begin{array}{l}\mathrm{OR}=0.93(0.50-1.74) \\
\quad p \text {-trend }=0.907\end{array}$ \\
\hline Zhang et al. 2017 [20] & $\begin{array}{l}\text { REACTION study; } 510 \text { cases, } 1327 \\
\text { controls }\end{array}$ & $\begin{array}{l}\text { Whole blood Se } \\
210 \text { (50) cases } \\
200 \text { (50) controls }\end{array}$ & Age, gender, BMI, insulin, SBP, DBP & $\begin{array}{l}\mathrm{OR}=2.69(1.31-3.49) \\
\quad p \text {-trend }<0.001\end{array}$ \\
\hline Lu et al. 2016 [21] & $\begin{array}{l}\text { Taipei medical center; } 303 \text { cases, } 544 \\
\text { controls }\end{array}$ & $\begin{array}{l}\text { Serum Se } \\
88.2(21.2)\end{array}$ & $\begin{array}{l}\text { Age, gender, current smoking, current drinking, } \\
\text { physical activity, waist circumference, HOMA-IR }\end{array}$ & $\begin{array}{l}\mathrm{OR}=3.79(2.17-6.32) \\
\quad p \text {-trend }<0.001\end{array}$ \\
\hline Simic et al. 2017 [22] & $\begin{array}{l}\text { The HUNT3 Survey; } 267 \text { self-reported } \\
\text { cases, } 609 \text { frequency-matched } \\
\text { controls }\end{array}$ & $\begin{array}{l}\text { Whole blood Se } \\
102.3 \text { cases } \\
102.3 \text { controls }\end{array}$ & $\begin{array}{c}\text { Age, sex, BMI, WHR, first-degree family history of } \\
\text { diabetes, smoking habits, area, education, economic } \\
\text { status }\end{array}$ & $\begin{array}{l}\mathrm{OR}=1.13(0.65-1.96) \\
\quad p \text {-trend }=0.530\end{array}$ \\
\hline Kohler et al. 2018 [23] & $\begin{array}{l}\text { Cross-sectional Selenium Trial, } \\
\qquad n=1714\end{array}$ & $\begin{array}{c}\text { Plasma Se } \\
\text { 143.6 (28.9) T2D } \\
138.7(27.2) \text { No T2D }\end{array}$ & $\begin{array}{l}\text { Age, sex, BMI, race, ethnicity, smoking, education, and } \\
\text { dietary intake of energy, protein, carbohydrate, total fat, } \\
\text { and total fiber }\end{array}$ & $\begin{array}{l}\mathrm{OR}=1.77(1.16-2.71) \\
\quad p \text {-trend }=0.007\end{array}$ \\
\hline Galan-Chilet et al. 2017 [17] & $\begin{array}{l}\text { Cross-sectional Hortega Study, } \\
\qquad n=1452 \\
\text { Prospective cohort, } n=1234,13.2 \\
\text { years follow-up }\end{array}$ & $\begin{array}{l}\text { Plasma Se } \\
\quad 84.2\end{array}$ & $\begin{array}{l}\text { Age, gender, education, urine cotinine, smoking status, } \\
\text { alcohol intake }\end{array}$ & $\begin{array}{c}\mathrm{OR}=1.97(1.14-3.41) \\
\quad p \text {-trend }=0.03 \\
\mathrm{HR}=1.80(0.98-3.31) \\
\quad p \text {-trend }=0.15\end{array}$ \\
\hline Wei et al. 2015 [24] & Cross-sectional in China, $n=5423$ & $\begin{array}{l}\text { FFQ } \\
43.51\end{array}$ & $\begin{array}{l}\text { Age, sex, education, employment, BMI, activity level, } \\
\text { WC, HTN, drinking, smoking condition, energy intake, } \\
\text { fiber intake, and nutritional supplementation status }\end{array}$ & $\begin{array}{l}\mathrm{OR}=1.52(1.01-2.28) \\
\quad p \text {-trend }=0.03\end{array}$ \\
\hline Laclaustra et al. 2009 [13] & $\begin{array}{l}\text { Cross-sectional NHANES 2003-2004, } \\
\qquad n=917\end{array}$ & $\begin{array}{l}\text { Serum } \\
137.1(19.9)\end{array}$ & $\begin{array}{l}\text { Sex, age, race, education, BMI, smoking, cotinine, } \\
\text { postmenopausal status, vitamin/mineral supplements } \\
\text { Age, sex, race/ethnicity, education, family income, } \\
\text { postmenopausal status, cigarette smoking, serum } \\
\text { cotinine, alcohol consumption, physical activity, BMI, }\end{array}$ & $\begin{array}{l}\mathrm{OR}=7.64(3.34-17.46) \\
\quad p \text {-trend }=0.002\end{array}$ \\
\hline Bleys et al. 2007 [14] & Cross-sectional NHANES III, $n=8876$ & $\begin{array}{c}\text { Serum } \\
126.5(1.0) \text { T2D } \\
125.7(21.0) \text { No T2D }\end{array}$ & $\begin{array}{l}\text { C-reactive protein, hypercholesterolemia, serum } \\
\text { triglycerides, HTN, GFR, vitamin/mineral } \\
\text { supplementation; intake of beta-carotene, vitamin C, } \\
\text { vitamin E; serum levels of albumin, alpha-carotene, } \\
\text { beta-carotene, beta-cryptoxanthin, lutein/zeaxanthin, } \\
\text { lycopene, uric acid, vitamin C, and vitamin E }\end{array}$ & $\begin{array}{l}\mathrm{OR}=1.57(1.16-2.13) \\
\quad p \text {-trend }=0.03\end{array}$ \\
\hline Gao et al. 2014 [15] & $\begin{array}{l}\text { Uppsala Longitudinal Study of Adult } \\
\text { Men (ULSAM), } n=936 \text { men, } \\
20 \text { years follow-up }\end{array}$ & $\begin{array}{l}\text { Baseline Serum } \\
\quad 75.6(14.3)\end{array}$ & $\begin{array}{l}\text { Age at baseline, BMI, cigarette smoking, leisure time } \\
\text { physical activity, education }\end{array}$ & $\begin{array}{l}\mathrm{OR}=1.06(0.83-1.38) \\
\quad p \text {-trend }=0.497\end{array}$ \\
\hline
\end{tabular}


Table 1. Cont

\begin{tabular}{|c|c|c|c|c|}
\hline Author, Year & Study Population & Exposure Mean (SD) $\mu \mathrm{g} / \mathrm{L}$ & Covariates & Key Findings RR (95\% CI) \\
\hline Stranges et al. 2010 [16] & $\begin{array}{l}\text { HORmones and Diet in the ETiology } \\
\text { of Breast Cancer (ORDET) Study, } \\
n=7182 \text { women, } 16 \text { years follow-up }\end{array}$ & $\begin{array}{c}\text { Baseline FFQ } \\
55.7\end{array}$ & $\begin{array}{l}\text { Age, education, menopausal status, BMI, smoking, } \\
\text { alcohol intake, energy intake, } \\
\text { saturated/polyunsaturated fatty acid ratio, animal } \\
\text { proteins, total carbohydrates, and weight change } \\
\text { (follow-up exam-baseline) }\end{array}$ & $\begin{array}{c}\mathrm{OR}=2.39(1.32-4.32) \\
\quad p \text {-trend }=0.005\end{array}$ \\
\hline Thompson et al. 2016 [26] & $\begin{array}{c}\text { Selenium and Celecoxib Trial, } \\
n=1640 \text { men, } 35.6 \text { and } 35.5 \text { months } \\
\text { follow-up in the placebo and Se arms, } \\
\text { respectively }\end{array}$ & $200 \mu \mathrm{g} /$ day selenized yeast & Random assignment to celecoxib, aspirin, and clinic & $\begin{array}{l}\mathrm{HR}=1.25(0.74-2.11) \\
p \text {-interaction age }=0.02 \mathrm{HR}= \\
2.21(1.04-4.67) \text { for age at } \\
\text { randomization } \geq 63 \text { years }\end{array}$ \\
\hline Lippman et al. 2009 [25] & $\begin{array}{l}\text { Selenium and Vitamin E Cancer } \\
\text { Prevention Trial (SELECT), } \\
n=17,448 \text { men in Se and placebo } \\
\text { arms only, median } 5.45 \text { years } \\
\text { follow-up }\end{array}$ & $200 \mu \mathrm{g} /$ day L-selenomethionine & Randomized controlled trial & $\mathrm{RR}=1.07(0.94-1.22)$ \\
\hline Stranges et al. 2007 [3] & $\begin{array}{l}\text { Nutritional Prevention of Cancer } \\
\text { (NPC) Trial, } n=1202 \text { men and } \\
\text { women, mean } 7.7 \text { years follow-up }\end{array}$ & $200 \mu \mathrm{g} /$ day selenized yeast & Age, sex, BMI, smoking status & $\begin{array}{l}\mathrm{IRR}=1.50(0.98-2.30) \\
\mathrm{HR}=1.55(1.03-2.33)\end{array}$ \\
\hline
\end{tabular}


Lowest Quantile of Se Highest Quantile of Se

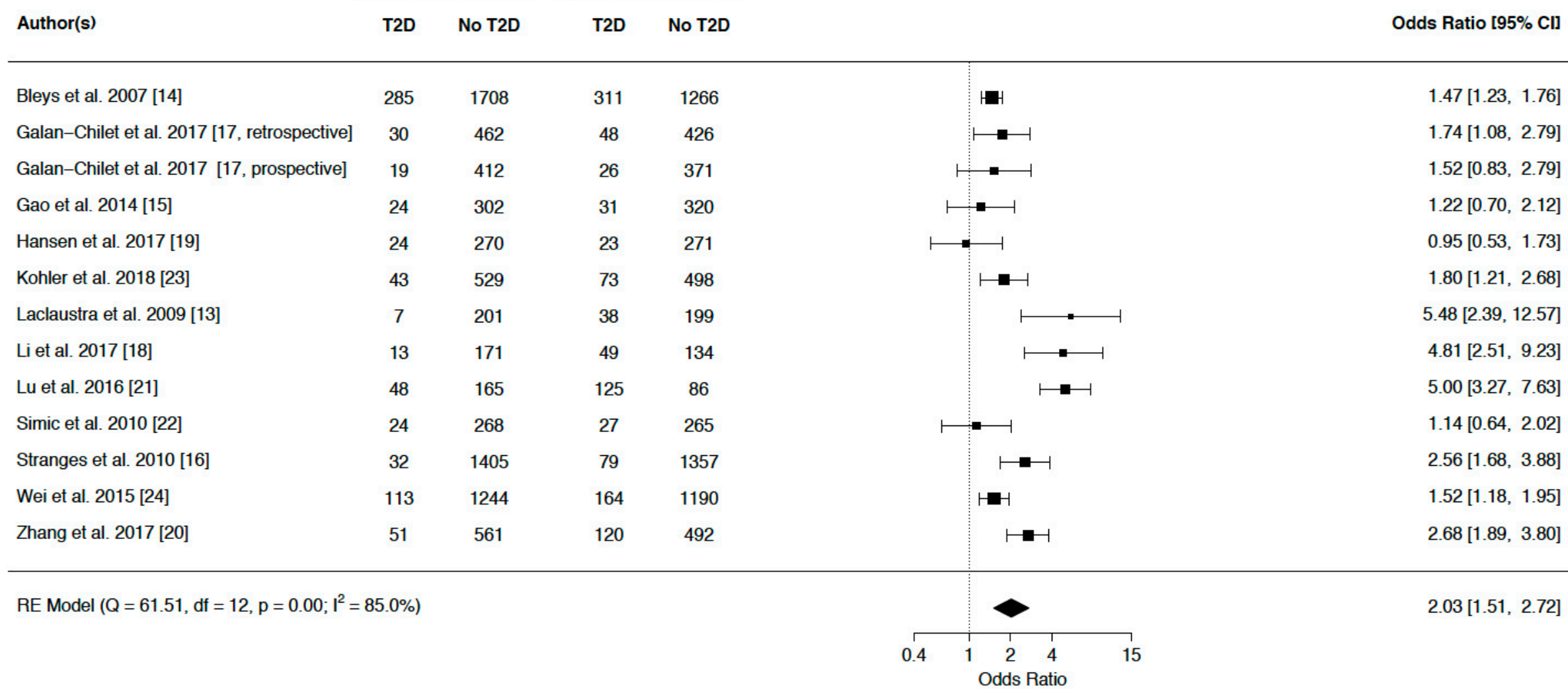

Figure 2. Odds ratios (95\% CIs) and summary statistics for the observational studies. 
Considerable heterogeneity was observed in the observational studies $\left(p=0.00, I^{2}=85.0 \%\right.$ ). Figure 3 demonstrates that for RCTs, there was a nonsignificant increased risk of T2D between those who received a Se supplement and those who were assigned placebo, with a pooled OR (95\% CI) of 1.18 (0.95-1.47). Moderate, nonsignificant heterogeneity was seen among the RCTs $\left(p=0.26, I^{2}=34.0 \%\right)$.

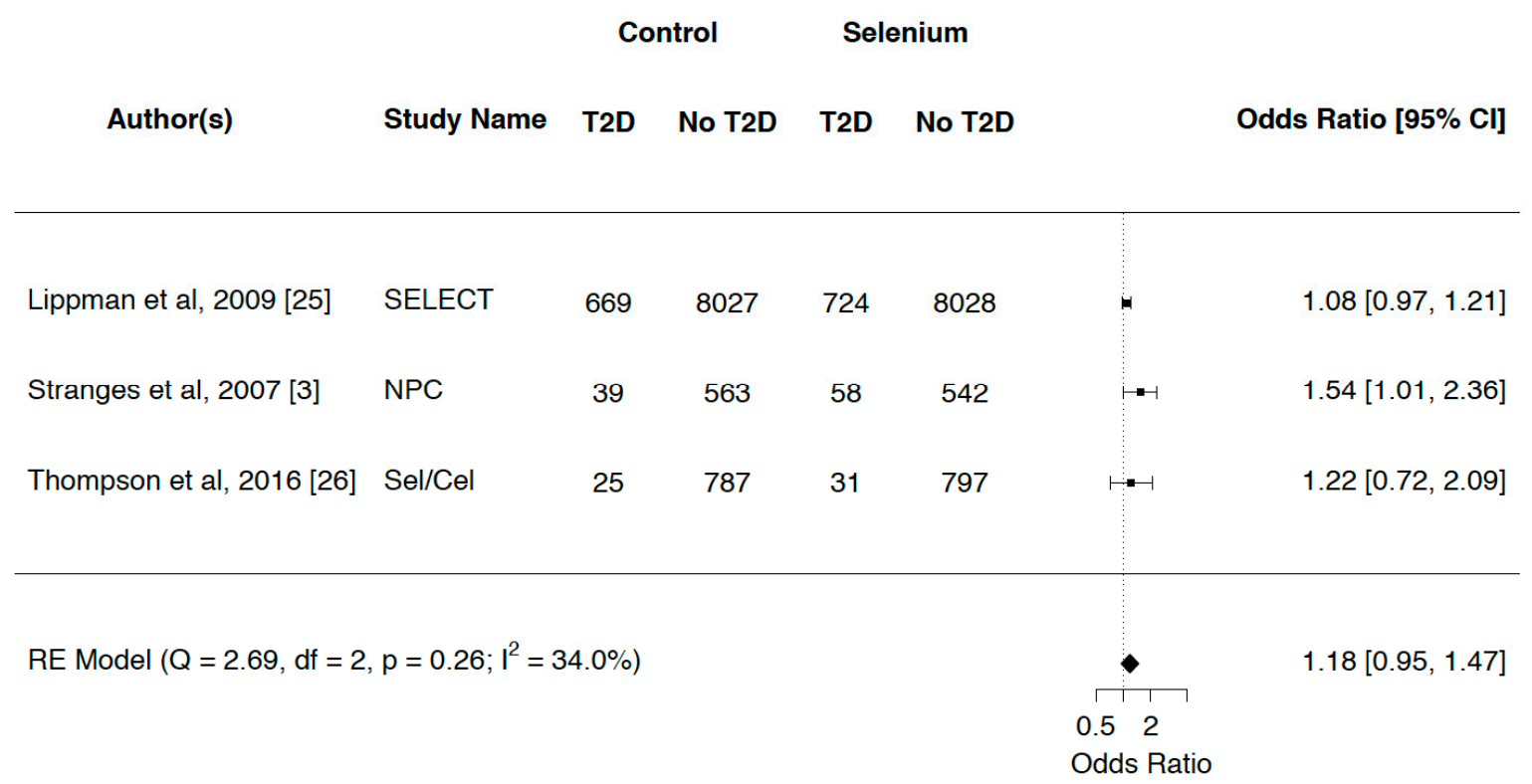

Figure 3. Odds ratios (95\% CIs) and summary statistics for randomized clinical trials (RCTs).

Figure 4 demonstrates a funnel plot for the treatment effect (log scale) plotted against the study size, as measured by the standard error of the treatment effect. The tendency toward asymmetry indicates evidence for publication bias.

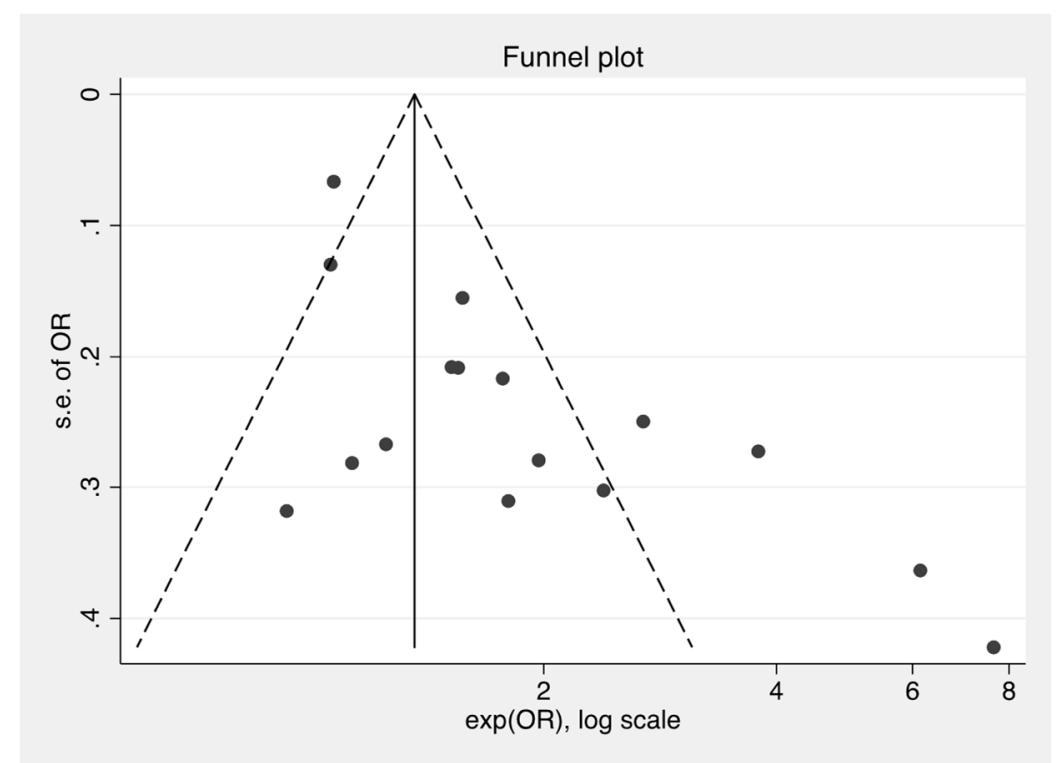

Figure 4. Funnel plot for publication bias.

\section{Discussion}

The results of this meta-analysis of Se and T2D showed that in RCTs, there is no significant effect of Se on the incidence of T2D. However, observational studies demonstrate a positive association between blood levels of Se and odds for prevalent T2D. Reconciliation of these findings is challenging, 
but there are several potential explanations for the differences in the clinical trial results compared to those from the observational studies.

Results from preclinical studies led to the further study of Se and glucose metabolism in large epidemiological studies in human populations. The work of Stranges et al. showed that within the NPC trial in which participants were followed for more than seven years, there was a statistically significant increase in T2D incidence among those who received Se compared to a placebo, with a hazard ratio and $95 \%$ confidence interval of 1.55 (1.03-2.33) [3]. These results were published while two additional large trials of Se supplementation were underway in the United States: SELECT and the Selenium Trial $[25,26]$, neither of which showed an overall statistically significant effect of Se supplementation on incident T2D. The Selenium Trial did report a significantly increased risk for T2D among the study participants who received Se and were older than 63 years of age [26]. Results of our previously published cross-sectional analyses of the Selenium Trial showed that baseline levels of Se were associated with a significantly higher odds of prevalent T2D, but that there was no age-related increase in risk of T2D [23]. These findings mirror those in the present meta-analysis of observational studies, as well as those of others [27], whereby a significantly increased risk for T2D was found among those with higher blood levels of Se $[13,14,23,24]$.

The largest observational study to date employed NHANES data to examine whether Se was related to T2D risk in a US study population of more than 8000 individuals [13]; those in the highest quantile for Se concentrations had an OR (95\% CI) of 1.57 (1.16-2.13) [13] for T2D compared to the lowest. In an Italian study population, Stranges et al. reported that the proportion of T2D cases in the highest tertile of baseline Se concentrations was significantly higher than those in the lowest tertile [28], and in a study conducted in China, individuals in the highest quartile of blood Se levels had a significantly higher odds of T2D compared to the lowest tertile, with an OR (95\% CI) of 2.69 (1.31-3.49) [20]. In contrast, in two studies conducted within the Nord-Trøndelag Health Survey (HUNT-3) in Norway, no significant association was found [19,22]. Overall, we identified a statistically significant direct relationship between Se and T2D in observational studies, but not among RCTs. The summary odds ratio $(95 \% \mathrm{CI})$ calculated in the present study of $1.18(0.95-1.47)$ is similar to that of another group that included RCTs with small numbers of participants for their estimates, and which reported a statistically significant finding of $1.11(1.01-1.22)$ [27]. Hence, the effect of selenium on T2D in RCTs remains equivocal, while those of observational studies appear to be more consistent.

The differences in the results from the observational studies and RCTs could arise from several different factors. The first is related to causality, which cannot be ascertained from observational studies. As shown in the current work, results from clinical trials provide scant evidence of a causal effect of Se on the development of T2D. It would be expected that if there were a notable impact of selenium on glucose dysregulation, it would likely be observed in the clinical trials that occurred after the NPC trial; notably, the SELECT and Selenium Trials $[25,26]$. These two trials used different intervention agents, with SELECT employing selenomethionine and the Selenium Trial, like the NPC trial, using selenized yeast. As reviewed by Rayman and Stranges, selenomethionine cannot be used directly for selenoprotein synthesis after consumption and must undergo catabolism first [7]. Experimental models with yeast also indicate that the effects of selenomethionine may vary depending on the presence of sulfur compounds that may compete with selenomethionine uptake [29]. In contrast, the Selenium Trial employed selenized yeast, which is the same agent that was shown in the work by Stranges et al. to be associated with a higher risk for T2D in the NPC trial [3]. Selenized yeast contains various amounts of selenomethionine in addition to numerous other selenium compounds of varying concentration and activity [30], highlighting the possibility that a selenium species other than selenomethionine might cause impaired insulin sensitivity or glucose metabolism. However, the Selenium Trial only demonstrated an increased risk for T2D for those at least 63 years of age at randomization, not overall ( $\mathrm{HR}=1.25,95 \%$ CI 0.74-2.11), among those who received the supplement, indicating that selenized yeast does not appear to exert effects on T2D that are greater than selenomethionine [26]. 
Rayman and Stranges suggested another possibility, which was that participants in the NPC trial were recruited due to the presence of nonmelanoma skin cancer, which may be related to arsenic exposure [7]. Thus, a potential interaction effect between selenium and arsenic may have led to higher rates of T2D in the Se-supplemented group compared to the placebo effect [7]. However, this does not explain the differences between the observational and clinical trial results observed in this meta-analysis. Residual confounding is a potential explanation, as it is possible that there is a confounding variable that is associated with both the exposure (blood selenium levels) and the outcome (T2D) [31]. However, the work included in this systematic review generally controlled for potential confounders such as age, sex, body mass index, energy intake, and smoking status. Therefore, there would need to be another as-yet-unknown variable that influences both exposure and outcome. There could also be individual characteristics of participants, such as genotype, that influence any biological effects of selenium and require further study.

Finally, the duration and timing of exposure to Se may be a key aspect of any effect on T2D. In the clinical trials, supplementation generally occurred for 3-5 years among older participants; observational studies may reflect longer-term, usual Se exposure through the diet. It is possible that lifelong consumption of Se is associated with risk for T2D while supplementation for a comparatively brief period is not. A primary challenge in examining nutrient relationships is determining whether the potential role is in the initiation, development, or exacerbation of disease or whether the variations in the observed nutrient levels are the consequence of disease sequelae. Additionally, nutrient effects may vary depending on the timing of inadequate or excessive nutrition. The SELECT and other selenium supplementation trials presumably examined the role of selenium as a strong antioxidant. However, as noted by Bellinger et al. [32], supplementation of selenium does not affect all selenoproteins equally and as previously discussed, choice within the supplemented form may also alter physiological uptake and use. In addition to its antioxidant properties, selenoproteins have a demonstrated effect in adipocyte differentiation [33]. This adipocyte differentiation effect may explain the increased T2D risk associated with dietary levels of selenium that presumably would have been similar during early formative years, whereas selenium supplementation during the later years of living may not play the same physiological role.

The strengths of this work include its comprehensive approach to review and meta-analyses and the inclusion of the most recent data for Se and T2D. We carefully followed the PRISMA guidelines for data collection, including the registration of our study with the PROSPERO International prospective register of systematic reviews. In addition, we assessed study quality before incorporating data into the meta-analysis, and also contacted authors for any missing data. However, the limitations of this study must also be addressed. First, there was significant variability in the study populations and designs, including the exposure definition used in the studies we found. Measurement of selenium exposure varied among the observational studies comprising dietary intake or biochemical assessment including serum, plasma, and whole blood. These factors may have contributed to the substantial heterogeneity found among the observational studies. Further, pooled estimates were unadjusted; therefore, uncontrolled confounding may have biased the observational pooled estimate.

\section{Conclusions}

The effects of T2D may be briefly described as inadequate secretion and/or sensitivity to insulin. Selenoproteins are critical physiological antioxidants, able to exert insulin-like properties that in excess may impair insulin signaling [32]. Additionally, pancreatic beta cells express selenoproteins, providing biological plausibility that selenium holds a role in T2D. However, the findings from this meta-analysis indicate consistent moderate associations only between high levels of dietary or serum selenium and prevalent T2D and inconsistent results among studies aimed at assessing incident T2D. Our analysis demonstrates no consistent evidence that Se supplementation plays a role in T2D development among adults. 
Author Contributions: E.T.J. developed the conception of the study, contributed to the statistical analysis and interpretation of the data, and drafted, revised, and finalized the manuscript. L.N.K. contributed to the study design and developed the systematic review protocol, was the first reviewer in the systematic review, supervised the statistical analysis, contributed to the interpretation of data, and drafted, revised, and finalized the manuscript. C.S. contributed to the study design, initiated the preliminary review, contributed to the interpretation of the data, and revised and finalized the manuscript. C.P.K. contributed to the study design, assisted in evaluating the quality of the studies, performed the statistical analysis, contributed to the interpretation of data, and drafted, revised, and finalized the manuscript. A.F. contributed to the study design, was the second reviewer in the systematic review, evaluated quality of the studies, contributed to the interpretation of data, and drafted, revised, and finalized the manuscript. P.H. contributed to the study design, performed the statistical analysis, interpreted the data, and drafted, revised, and finalized the manuscript. K.S., H.-H.S.C., K.B., N.E., J.F., and P.L. contributed to data interpretation and preparation of the manuscript.

Funding: Funding was provided from the following sources: National Cancer Institute Cancer Center Support Grant P30 CA023074, NIH/NCI R01CA151708 (ETJ), NIH/NCI P01 CA041108 (PL); and NIH/NCI R01CA151708 (PL). The funding sources had no role in the interpretation or publication of results. Services in support of the research project were generated by the University of Arizona Cancer Center Biostatistics Shared Resource, supported, in part, with funding from NIH-NCI Cancer Center Support Grant P30 CA023074.

Acknowledgments: We wish to thank D Jean McClelland, MLS, for her input on databases to include for the systematic review and relevant search terms.

Conflicts of Interest: The authors declare no conflict of interest.

\section{References}

1. Clark, L.; Combs, G.F., Jr.; Turnbull, B.W.; Slate, E.H.; Chalker, D.K.; Chow, J.; Davis, L.S.; Glover, R.A.; Graham, G.F.; Gross, E.G.; et al. Effects of selenium supplementation for cancer prevention for cancer prevention in patients with carcinoma of the skin: A randomized controlled trial. JAMA 1996, 276, 1957-1963. [CrossRef] [PubMed]

2. Duffield-Lillico, A.J.; Reid, M.E.; Turnbull, B.W.; Combs, G.F.; Slate, E.H.; Fischbach, L.A.; Marshall, J.R.; Clark, L.C. Baseline characteristics and the effect of selenium supplementation on cancer incidence in a randomized clinical trial: A summary report of the nutrition prevention of cancer trial. Cancer Epidemiol. Biomark. Prev. 2002, 11, 630-639. [PubMed]

3. Stranges, S.; Marshall, J.R.; Natarajan, R.; Donahue, R.P.; Trevisan, M.; Combs, G.F.; Cappuccio, F.P.; Ceriello, A.; Reid, M.E. Effects of long-term selenium supplementation on the incidence of type 2 diabetes: A randomized trial. Ann. Intern. Med. 2007, 147, 217-223. [CrossRef] [PubMed]

4. McNeill, J.H.; Delgatty, H.L.; Battell, M.L. Insulinlike effects of sodium selenate in streptozocin-induced diabetic rats. Diabetes 1991, 40, 1675-1678. [CrossRef] [PubMed]

5. Mueller, A.S.; Pallauf, J. Compendium of the antidiabetic effects of supranutritional selenate doses. In vivo and in vitro investigations with type ii diabetic $d b / d b$ mice. J. Nutr. Biochem. 2006, 17, 548-560. [CrossRef] [PubMed]

6. Papp, L.V.; Lu, J.; Holmgren, A.; Khanna, K.K. From selenium to selenoproteins: Synthesis, identity, and their role in human health. Antioxid. Redox Signal. 2007, 9, 775-806. [CrossRef]

7. Rayman, M.P.; Stranges, S. Epidemiology of selenium and type 2 diabetes: Can we make sense of it? Free Radic. Biol. Med. 2013, 65, 1557-1564. [CrossRef]

8. Battin, E.E.; Brumaghim, J.L. Antioxidant activity of sulfur and selenium: A review of reactive oxygen species scavenging, glutathione peroxidase, and metal-binding antioxidant mechanisms. Cell Biochem. Biophys. 2009, 55, 1-23. [CrossRef]

9. McClung, J.P.; Roneker, C.A.; Mu, W.; Lisk, D.J.; Langlais, P.; Liu, F.; Lei, X.G. Development of insulin resistance and obesity in mice overexpressing cellular glutathione peroxidase. Proc. Natl. Acad. Sci. USA 2004, 101, 8852-8857. [CrossRef]

10. Loh, K.; Deng, H.; Fukushima, A.; Cai, X.; Boivin, B.; Galic, S.; Bruce, C.; Shields, B.J.; Skiba, B.; Ooms, L.M.; et al. Reactive oxygen species enhance insulin sensitivity. Cell Metab. 2009, 10, 260-272. [CrossRef]

11. Moher, D.; Liberati, A.; Tetzlaff, J.; Altman, D.G.; Group, P. Preferred reporting items for systematic reviews and meta-analyses: The prisma statement. J. Clin. Epidemiol. 2009, 62, 1006-1012. [CrossRef] [PubMed]

12. Critical appraisals skills programme (casp). Available online: https://casp-uk.net/casp-tools-checklists / (accessed on 6 May 2018). 
13. Laclaustra, M.; Navas-Acien, A.; Stranges, S.; Ordovas, J.M.; Guallar, E. Serum selenium concentrations and diabetes in U.S. Adults: National health and nutrition examination survey (nhanes) 2003-2004. Environ. Health Perspect. 2009, 117, 1409-1413. [CrossRef] [PubMed]

14. Bleys, J.; Navas-Acien, A.; Guallar, E. Serum selenium and diabetes in U.S. Adults. Diabetes Care 2007, 30, 829-834. [CrossRef] [PubMed]

15. Gao, H.; Hagg, S.; Sjogren, P.; Lambert, P.C.; Ingelsson, E.; van Dam, R.M. Serum selenium in relation to measures of glucose metabolism and incidence of type 2 diabetes in an older swedish population. Diabet. Med. 2014, 31, 787-793. [CrossRef] [PubMed]

16. Stranges, S.; Sieri, S.; Vinceti, M.; Grioni, S.; Guallar, E.; Laclaustra, M.; Muti, P.; Berrino, F.; Krogh, V. A prospective study of dietary selenium intake and risk of type 2 diabetes. BMC Public Health 2010, 10, 564. [CrossRef] [PubMed]

17. Galan-Chilet, I.; Grau-Perez, M.; De Marco, G.; Guallar, E.; Martin-Escudero, J.C.; Dominguez-Lucas, A.; Gonzalez-Manzano, I.; Lopez-Izquierdo, R.; Briongos-Figuero, L.S.; Redon, J.; et al. A gene-environment interaction analysis of plasma selenium with prevalent and incident diabetes: The hortega study. Redox Biol. 2017, 12, 798-805. [CrossRef] [PubMed]

18. Li, X.T.; Yu, P.F.; Gao, Y.; Guo, W.H.; Wang, J.; Liu, X.; Gu, A.H.; Ji, G.X.; Dong, Q.; Wang, B.S.; et al. Association between plasma metal levels and diabetes risk: A case-control study in china. Biomed. Environ. Sci. 2017, 30, 482-491. [PubMed]

19. Hansen, A.F.; Simic, A.; Asvold, B.O.; Romundstad, P.R.; Midthjell, K.; Syversen, T.; Flaten, T.P. Trace elements in early phase type 2 diabetes mellitus-a population-based study. The hunt study in norway. J. Trace Elem. Med. Biol. 2017, 40, 46-53. [CrossRef]

20. Zhang, H.; Yan, C.; Yang, Z.; Zhang, W.; Niu, Y.; Li, X.; Qin, L.; Su, Q. Alterations of serum trace elements in patients with type 2 diabetes. J. Trace Elem. Med. Biol. 2017, 40, 91-96. [CrossRef]

21. Lu, C.W.; Chang, H.H.; Yang, K.C.; Kuo, C.S.; Lee, L.T.; Huang, K.C. High serum selenium levels are associated with increased risk for diabetes mellitus independent of central obesity and insulin resistance. BMJ Open Diabetes Res. Care 2016, 4, e000253. [CrossRef]

22. Simic, A.; Hansen, A.F.; Asvold, B.O.; Romundstad, P.R.; Midthjell, K.; Syversen, T.; Flaten, T.P. Trace element status in patients with type 2 diabetes in norway: The hunt3 survey. J. Trace Elem. Med. Biol. 2017, 41, 91-98. [CrossRef]

23. Kohler, L.N.; Florea, A.; Kelley, C.P.; Chow, S.; Hsu, P.; Batai, K.; Saboda, K.L.; Lance, P.; Jacobs, E.T. Higher plasma selenium concentrations are associated with increased odds of prevalent type 2 diabetes. J. Nutr. 2018. [CrossRef] [PubMed]

24. Wei, J.; Zeng, C.; Gong, Q.Y.; Yang, H.B.; Li, X.X.; Lei, G.H.; Yang, T.B. The association between dietary selenium intake and diabetes: A cross-sectional study among middle-aged and older adults. Nutr. J. 2015, 14, 18. [CrossRef] [PubMed]

25. Lippman, S.M.; Klein, E.A.; Goodman, P.J.; Lucia, M.S.; Thompson, I.M.; Ford, L.G.; Parnes, H.L.; Minasian, L.M.; Gaziano, J.M.; Hartline, J.A.; et al. Effect of selenium and vitamin e on risk of prostate cancer and other cancers: The selenium and vitamin e cancer prevention trial (select). JAMA 2009, 301, 39-51. [CrossRef] [PubMed]

26. Thompson, P.A.; Ashbeck, E.L.; Roe, D.J.; Fales, L.; Buckmeier, J.; Wang, F.; Bhattacharyya, A.; Hsu, C.H.; Chow, H.H.; Ahnen, D.J.; et al. Selenium supplementation for prevention of colorectal adenomas and risk of associated type 2 diabetes. J. Natl. Cancer Inst. 2016, 108. [CrossRef] [PubMed]

27. Vinceti, M.; Filippini, T.; Rothman, K.J. Selenium exposure and the risk of type 2 diabetes: a systematic review and meta-analysis. Eur. J. Epidemiol. 2018, 33, 789-810. [CrossRef] [PubMed]

28. Stranges, S.; Galletti, F.; Farinaro, E.; D’Elia, L.; Russo, O.; Iacone, R.; Capasso, C.; Carginale, V.; De Luca, V.; Della Valle, E.; et al. Associations of selenium status with cardiometabolic risk factors: An 8-year follow-up analysis of the olivetti heart study. Atherosclerosis 2011, 217, 274-278. [CrossRef]

29. Lazard, M.; Dauplais, M.; Blanquet, S.; Plateau, P. Trans-sulfuration pathway seleno-amino acids are mediators of selenomethionine toxicity in saccharomyces cerevisiae. J. Biol. Chem. 2015, 290, 10741-10750. [CrossRef]

30. Larsen, E.H.; Hansen, M.; Paulin, H.; Moesgaard, S.; Reid, M.; Rayman, M. Speciation and bioavailability of selenium in yeast-based intervention agents used in cancer chemoprevention studies. J. AOAC Int. 2004, 87, 225-232. 
31. Liang, W.; Zhao, Y.; Lee, A.H. An investigation of the significance of residual confounding effect. Biomed. Res. Int. 2014, 2014, 658056. [CrossRef]

32. Bellinger, F.P.; Raman, A.V.; Reeves, M.A.; Berry, M.J. Regulation and function of selenoproteins in human disease. Biochem. J. 2009, 422, 11-22. [CrossRef] [PubMed]

33. Steinbrenner, H.; Speckmann, B.; Klotz, L.O. Selenoproteins: Antioxidant selenoenzymes and beyond. Arch. Biochem. Biophys. 2016, 595, 113-119. [CrossRef] [PubMed]

(C) 2018 by the authors. Licensee MDPI, Basel, Switzerland. This article is an open access article distributed under the terms and conditions of the Creative Commons Attribution (CC BY) license (http://creativecommons.org/licenses/by/4.0/). 